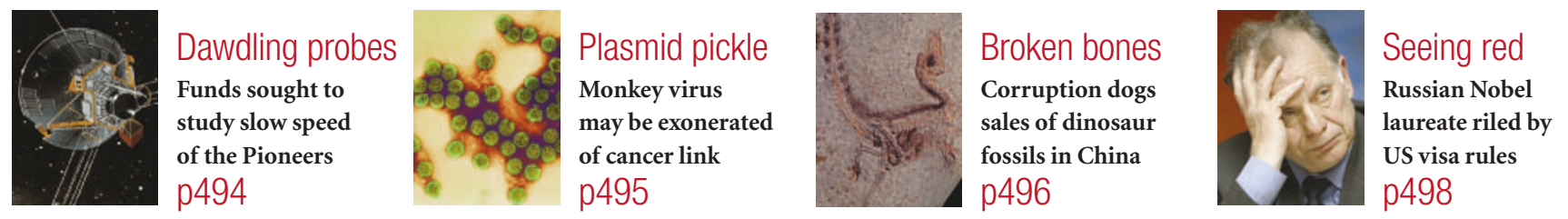

\title{
Global AIDS trial denied patients as US balks at generic drug use
}

\section{Erika Check, Washington}

US opposition to generic AIDS drugs is unnecessarily delaying the progress of a major international clinical trial, critics say.

The \$120-million trial, which is known as Strategies for Management of Anti-Retroviral Therapy, or SMART, is sponsored by the US National Institute of Allergy and Infectious Diseases (NIAID). It aims to enroll 6,000 patients to answer several questions about antiretroviral treatments for HIV, including whether they should be used early and aggressively, or whether treatment should only commence once a patient's immune system begins to fail. But the trial is running behind schedule because NIAID has balked at enrolling patients who take generic versions of the antiretroviral drugs.

According to trial organizers in the United States and elsewhere, patients in Argentina, Brazil and Peru were expected to join the trial earlier this year. But leaders of AIDS trials in South America and Thailand say they were told this summer that their patients would not be able to take part in SMART, because these people are all taking generic versions of brand-name AIDS medicines and those versions have not been approved by the US Food and Drug Administration (FDA). They say the instruction was handed down by the institute, which is part of the US health department's National Institutes of Health (NIH).

\section{Written complaint}

"We are told that, in SMART, no drugs not approved by FDA must be used," wrote Bernard Hirschel, leader of an AIDS trial covering Switzerland, Thailand and Australia, in an e-mail sent to colleagues earlier this month. A copy of his e-mail was given to Nature by a third party last week.

The Bush administration said earlier this

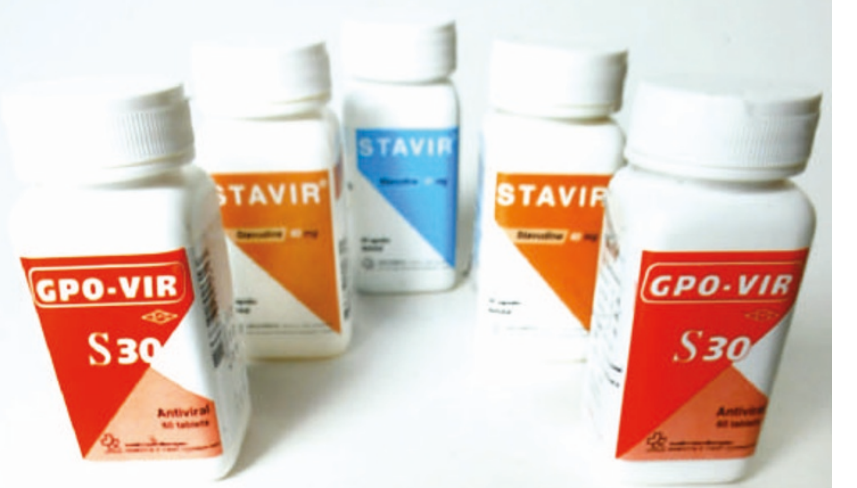

statement. "My sense is that what is driving this is a desire to protect the brand-name companies' market share," says Gregg Gonsalves, head of treatment and prevention advocacy at Gay Men's Health Crisis in New York.

Fauci told Nature on 23 September that the NIH had no blanket policy to exclude generic drugs from its international trials. He said the agency would evaluate countries on an individual basis.

"If a country has data that the drugs they're using appear to be comparable to the drugs in other countries, and they want to enroll in this trial, we see no reason why they have to switch to FDAapproved drugs," Fauci said. But he would not say whether any of the countries trying to get into the SMART trial would meet this standard.

\section{Negotiations stalled}

Meanwhile, the delays have kept hundreds of patients from joining SMART. Brazil, Argentina and Peru are waiting for NIAID to sign a contract confirming their participation, but that step has repeatedly been delayed, say researchers. The issue has also stalled negotiations with another year that it would not allow recipients of aid under the US President's Emergency Plan for AIDS Relief to buy generic drugs with aid money until they are approved by the FDA. But the NIH is not buying drugs for any patients in the SMART trial. Anthony Fauci, head of NIAID, says it is concerned about generic drugs onlybecause they lack approval.

"NIH funded clinical trials in the developing world must meet the same standards as clinical trials conducted in the developed world, e.g. that the drugs being used are safe and meet accepted standards," Fauci wrote in a 16 September e-mail, in response to Hirschel's concerns.

But activists are sceptical about that important potential participant — Thailand.

The delays have implications for AIDS care around the world. SMART was expected to enroll 2,264 patients this year; but has so far enrolled only 792. The South American and Thai arms of the trial would add 733 patients to the total for this year.

"Peru, Brazil and Argentina are in a holding pattern, and Thailand isn't even there because it got held up before it got started," says Fred Gordin, an infectious diseases specialist at the Veterans Affairs Medical Center in Washington DC and head of the group that has been funded by NIAID to run the SMART trial. "We really need these countries on board," he says. 